\title{
Solano Trindade e a poética da resistência: na ausência, a existência
}

Arlindo Rebechi Junior

Docente do Departamento de Ciências Humanas da Faculdade de Arquitetura, Artes e Comunicação da Universidade Estadual Paulista, atua na graduação e no Programa de Pós-Graduação em Comunicação. Doutor em Literatura Brasileira pela FFLCH/USP.

E-mail: arlindo.rebechi@unesp.br

Resumo: Este artigo tem o propósito de apontar algumas linhas de força presentes na poesia do recifense Solano Trindade (1908-1974), uma das figuras mais importantes da poesia afro-brasileira. Sua produção poética concentrou-se entre os anos 1930 e 1960, período em que se estabeleceu entre a militância a favor das populações negras e os movimentos de uma arte popular, participando do Teatro Experimental do Negro (TEN) e fundando o Teatro Popular Brasileiro (TPB). Sua poesia também esteve circunscrita a esses dois limites de atuação e consegue preencher uma lacuna: ele vai ao passado dos negros e negras do Brasil como um ato de resistência, dá existência ao que estava silenciado.

Palavras-chave: Solano Trindade (19081974); poesia afro-brasileira; literatura brasileira.
Abstract: This article aims to point out some lines of force in the poetry of Solano Trindade (1908-1974), one of the most important figures in Afro-Brazilian poetry. Trindade's artistic production was concentrated between the 1930's and 1960's, period within which the author established himself as a militant in favor of black populations and popular art movements, participating in the Teatro Experimental do Negro (TEN) and founding the Teatro Popular Brasileiro (TPB). His poetry was also circumscribed within these two limits of action, managing to fill a gap by recovering the past of Black men and women in Brazil as an act of resistance, affirming the existence of what was socially silenced.

Keywords: Solano Trindade (1908-1974); afro-Brazilian poetry; Brazilian literature. 


\section{POESIA E RESISTÊNCIA EM SOLANO TRINDADE}

Em qualquer época, o prestígio social de poetas e artistas está sujeito a muitas condições e variáveis: a crítica do seu momento, os códigos culturais difundidos em um período, os temas de maior interesse social, os interesses econômicos de grupos e até mesmo as visões que balizam o que uma sociedade concebe como arte ou não em um determinado momento. Sem dúvida alguma, os cânones literários resultam de muitas condicionantes sociais, que são permeáveis às assimetrias sociais existentes. Nessa máquina que não cessa, há ruins poetas lembrados e bons poetas esquecidos. Passado algum tempo, com o filtro implacável da passagem das épocas, alguns desse maus poetas, lembrados outrora, ganham o lugar no esquecimento. E outros bons e esquecidos, para a nossa sorte, são lembrados e ganham um lugar de destaque que deveriam ter tido ainda em vida.

O poeta Solano Trindade, se não foi um poeta, em sua época, esquecido por seus pares, obteve um destaque e reconhecimento aquém do que sua poesia nos proporciona e merece. Num país, como o nosso, onde a cada dia jovens negros e negras são assassinados em muitas periferias de todas as grandes cidades, Solano Trindade deveria ser poeta obrigatório nas escolas. Por várias razões, é um poeta do povo, é um poeta para os jovens do Brasil. Solano Trindade consegue realizar algo um tanto raro em matéria de poesia: ao mesmo tempo em que percorre uma dicção de alta qualidade de composição e sem imitações, à maneira academicista, de escolas ou de poetas canônicos, sua poesia apresenta um alto engajamento político. Poesia e política ascendem a um só tempo, sem a vulgaridade panfletária comum em empreitadas desse tipo.

Natural do Recife, em Pernambuco, nascido em 1908, Solano Trindade não demorou a entrar na militância política e na militância cultural em prol das causas dos negros e negras do Brasil. Em 1934 - ano também do I Congresso Afro-Brasileiro, no qual Solano havia participado ativamente -, o poeta funda a Frente Negra Pernambucana (FNP), espécie de braço local da Frente Negra Brasileira (FNB), cujos propósitos era o de fortalecimento da identidade racial das populações brasileiras de negros e negras e consolidação de um espaço de debate em torno da questão racial no Brasil. Dois anos depois, em 1936, ligado à atuação da FNP, Solano Trindade, junto aos artistas Vicente de Lima e Miguel Barros, fundaram o Centro de Cultura Afro-brasileiro, em Recife. Além de atividades de formação e culturais, o Centro apresentava-se como um lugar de resistência e de reflexão sobre o pensamento negro, muitas vezes em contraposição à ideologia hegemônica que marcou os debates raciais nos anos 1930 no Brasil.

Ainda nos anos 1930, Solano Trindade publicou, em uma edição de autoria própria, sua primeira obra poética, intitulada Poemas negros (1936). Quase 10 anos depois, ele conseguiria publicar o seu segundo livro, chamado Poemas d'uma vida simples (1944), que, segundo o próprio autor, teve seus exemplares apreendidos durante sua primeira prisão, ocorrida no mesmo ano:

Em 1944, tive minha primeira prisão política. Eu era membro da Sociedade Amigos da América. Fui preso pela polícia de Dutra. O negócio era contra 
Manuel Rabelo e contra o manifesto de Mangabeira. [...] Eu morava em Caxias. Quatro homens fortes foram me buscar. [...] Levaram comigo 39 exemplares de meu livro "Poemas D’uma Vida Simples". Depois passaram-me para um cubículo, onde havia doze presos ${ }^{1}$.

Em paralelo à atividade de poeta, Solano Trindade também esteve ligado ao universo do teatro. Na capital federal da época, nos anos 1940, teve uma participação no Teatro Experimental do Negro (TEN), então liderado por Abdias Nascimento. Não só atuando com a montagem de espetáculos teatrais, o TEN também realizava outras atividades, ora como departamento de estudos relacionados aos negros, por meio de seu braço, o Instituto Nacional do Negro, e ora com o seu museu, o Museu do Negro. Por todos esses motivos, o TEN foi responsável por uma série de eventos importantes no âmbito nacional: é o caso da Conferência Nacional do Negro, em 1949; do Primeiro Congresso do Negro Brasileiro, em 1950; e da Convenção Nacional do Negro, em 1945.

Em 1950, Solano Trindade junto com Margarida Trindade e Edison Carneiro fundam o Teatro Popular Brasileiro (TPB). Com esse grupo, foram produzidos vários espetáculos em que personagens eram protagonizadas por pessoas menos favorecidas na sociedade brasileira, por domésticas, operários, entre outros. As exibições percorriam o território brasileiro e também chegaram a lugares distantes, como a Europa.

Sem contar com nenhum apoio oficial do Estado para o TPB e já vendo o grupo formado se dispersar, Solano, no início de 1958, decide por fixar residência em São Paulo, onde ele vislumbrava a possibilidade de mais exibições teatrais e a promessa de um contrato na televisão. No mesmo ano, ele lança sua terceira obra, Seis tempos de poesia (1958). Nesse livro aparece a carta datada de 1946, de Roger Bastide, sociólogo francês, sobre sua apreciação dos poemas de Trindade. Num dos trechos, Bastide diz o seguinte:

Aprecio esses poemas que realizam uma síntese entre o passado e o futuro, entre as aspirações de reis proletarizados e as canções do folclore, entre o amor moderno, à sombra das chaminés de usina, e o amor místico, sob o olhar dos orixás².

Em 1961, Solano Trindade publica o seu último livro em vida: Cantares ao meu povo (1961). Na ocasião do lançamento do livro, o poeta, em uma entrevista ao jornal Diário da Noite, nos chama a atenção para o que poderia ser uma autointerpretação da sua própria dicção poética, que vale transcrever pelo seu teor autobiográfico:

Depois veio a fase da poesia negra, que começou em 1940, e a poesia social, como consequência dessa coisa toda [...] A própria declamação deve ser diferente na poesia negra. Deve ser ritmada, livre da preocupação ocidental do termo estético ${ }^{3}$.

\section{QUAL VOZ? QUAL POESIA?}

Cabe começar por dois poemas que confrontam o próprio fazer poético:
1. TRINDADE, Solano. Solano Trindade: o poeta do povo. Organização de Raquel Trindade. São Paulo: Cantos e Prantos, 1999, p. 124.

2. BASTIDE, Roger. [Correspondência]. Destinatário: Solano Trindade. São Paulo, 4 out. 1946. 1 carta pessoal. In: TRINDADE, Solano. Seis tempos de poesia. São Paulo: Edição H. Mello, 1958, p. 87.

3. POESIA Negra, social e mística no livro de Solano Trindade. Diário da Noite, São Paulo, 6 out. 1961. 


\author{
Advertência \\ Há poetas que só fazem versos de amor \\ Há poetas herméticos e concretistas \\ enquanto se fabricam \\ bombas atômicas e de hidrogênio \\ enquanto se preparam \\ exércitos para guerra \\ enquanto a fome estiola os povos... \\ Depois \\ eles farão versos de pavor e de remorso \\ e não escaparão ao castigo \\ porque a guerra e a fome \\ também os atingirão \\ e os poetas cairão no esquecimento... ${ }^{4}$ \\ Chamada \\ Poetas despertai enquanto é tempo \\ antes que a poesia do mundo \\ vá-se embora \\ antes que caia sobre o homem \\ um peso insuportável... \\ Vinde correndo \\ cantar o vosso canto de Amor \\ para que as crianças \\ não sucumbam \\ Vinde com a vossa poesia \\ socorrer as mulheres \\ para que elas não caiam em desespero \\ Vinde poetas \\ pois vós \\ conheceis o segredo da vida...
}

Uma das questões centrais que a arte moderna trouxe, em especial a literatura, foi intensificar as formas de refletir sobre o próprio ato de realizar um objeto artístico, levando muitas vezes ao debate, via um discurso metalinguístico, sobre os limites da representação artística. Ao longo do século XX, muitos poetas brasileiros assumiram o viés de escrever sobre o ato de escrever. Em algumas dessas possibilidades assumidas: há poeta que indaga sobre a linguagem que joga com os sentidos e o real; há o poeta que indaga sobre si mesmo, sobre suas dificuldades em decifrar o mundo e ajustá-lo à linguagem poética e ao

4. TRINDADE, Solano. Poemas antológicos de Solano Trindade. Organização de Zenir Campos Reis. São Paulo: Nova Alexandria, 2011, p. 17

5. Ibidem, p. 24. rigor de suas construções; há poeta que indaga sobre o papel social do próprio poeta e sua arte, entre muitas possibilidades. Os dois poemas acima de Solano Trindade enquadram-se nessa última categoria.

Em "Advertência", a zona metalinguística do poema é traçada pela oposição entre o fazer de um tipo de poesia (a dos "versos de amor", a dos "poetas herméticos e concretistas") e o elemento destrutivo do real (fabricação de "bombas 
atômicas e de hidrogênio", aparições da guerra e da fome). Na estrofe seguinte, sua crítica é ainda mais contundente: nutrido por esses mesmos motivos destrutivos, os poetas cantam seus versos de "pavor e remorso" num tempo em que não há muito por fazer, pois também estão atingidos pela guerra, fome e, por fim, talvez em função desses outros dois, pelo esquecimento. No fundo, sua indagação passa por refletir sobre o direito à poesia e o seu real valor em face da destruição trazida por mazelas que não cessam por um só instante. Mas sua indagação também sugere, nas entrelinhas, o tipo de poesia almejada pelo poeta. Uma poesia, por assim dizer, de corpo-a-corpo com o real, que enfrenta o real.

Em "Chamada", o trabalho metalinguístico é feito em outra chave. Resulta de uma iniciativa de Trindade em chamar os poetas para uma missão. A eles cabem fazer a poesia diante de um mundo de crises sem precedentes, um mundo dilacerado pela exploração de corpos que são operados por condicionantes externas a eles. É preciso realizar a poesia enquanto ainda há tempo para isso: "antes que a poesia do mundo / vá-se embora / antes que caia sobre o homem / um peso insuportável...”. Seu chamamento é diante de uma nova dor que o mundo vive, mas não só isso. O poema traz em si uma confiança sobre o papel da própria poesia como motor de transformação e sobre o papel da linguagem como fator humanista diante das experiências históricas da exploração e do domínio de uns sobre os outros.

Ainda mais contundente que esses dois anteriores é o poema "Esperemos", transcrito abaixo:

Eu ia fazer um poema para você mas me falaram das crueldades nas colônias inglesas

e o poema não saiu

ia falar do seu corpo

de suas mãos

amada

quando soube que a polícia espancou um companheiro

e o poema não saiu

ia falar em canções

no belo da natureza

nos jardins

nas flores

quando falaram-me em guerra

e o poema não saiu

perdão amada

por não ter construído o seu poema

amanhã esse poema sairá

esperemos ${ }^{6}$.

O verbo esperar, entre suas muitas acepções, pode ter o sentido de confiar que algo ou alguma coisa pode acontecer. Se ainda realizássemos uma sintonia mais fina do sentido trazido pelo uso de "esperemos" - na abertura, 
com o título; e no fechamento, com a última palavra -, poderíamos remeter a uma ideia de expectativa com algo ou alguma coisa que ainda devemos ter a esperança de acontecer. O poema examina o passado, o presente e coloca um fio de esperança no futuro. Do passado vem aquilo que arruína a tarefa do poeta em realizar o seu poema que "não saiu". Do presente se justifica seu perdão e abre o caminho para sua esperança futura: rememoradas as ruínas das tragédias do passado, será possível ter o amanhecer com um novo poema? Aquilo que era a condicional de uma certa incerteza, demarcada pelas locuções verbais ("ia fazer", "ia falar"), abre a possibilidade de um novo momento: a certeza do presente no futuro, em que "esse poema sairá".

É preciso, todavia, lembrar que o lugar da esperança trazida por Solano Trindade sempre encontrava uma manifestação crítica da própria realidade circundante. É o caso do lugar de esperança nas indagações lançadas no poema "Amanhã será melhor", quando o poeta deflagra sua voz de denúncia das contradições presentes no mundo capitalista, numa dicção típica da melhor poesia social:

Nas manhãs de sol

$\mathrm{O}$ trabalhador

Sai pra trabalhar,

Nas manhãs chuvosas

O trabalhador

Sai pra trabalhar.

É a natureza

E o trabalhador

Sempre a trabalhar

Que constrói o mundo

Que constrói a vida

Sempre a trabalhar.

Quais as esperanças

Do trabalhador?

Não posso dizer

Ele dá tudo

Nada ele tem

Quais as esperanças

Do trabalhador?

Pelos campos

Pelas fábricas

Estou sempre a perguntar

Quais as esperanças

Do trabalhador?

Nas zonas miseráveis

Eu fico a perguntar

Quais as esperanças

Do trabalhador? 
Nos hospitais

Nas cadeias

$\mathrm{Eu}$ fico a meditar

Quais as esperanças

Do trabalhador?

Toma forma de ritmo

Toma forma de canto

Sempre a mesma pergunta

Quais as esperanças

Do trabalhador??

Ligado à voz de uma poesia de cunho social está também um dos seus poemas mais conhecidos, "Tem gente com fome", escrito para sua seleta de poemas dos anos 1940. Cabe transcrevê-lo aqui:

Trem sujo da Leopoldina correndo correndo parece dizer tem gente com fome tem gente com fome tem gente com fome

Piiiiii

Estação de Caxias de novo a dizer de novo a correr tem gente com fome tem gente com fome tem gente com fome

Vigário Geral

Lucas

Cordovil

Brás de Pina

Penha Circular

Estação da Penha

Olaria

Ramos

Bom Sucesso

Carlos Chagas

Triagem, Mauá

trem sujo da Leopoldina

correndo correndo

parece dizer

tem gente com fome

tem gente com fome

tem gente com fome

Tantas caras tristes querendo chegar 
em algum destino

em algum lugar

Trem sujo da Leopoldina

correndo correndo

parece dizer

tem gente com fome

tem gente com fome

tem gente com fome

Só nas estações

quando vai parando

lentamente começa a dizer

se tem gente com fome

dá de comer

se tem gente com fome

dá de comer

se tem gente com fome

dá de comer

Mas o freio de ar

todo autoritário

manda o trem calar

Pisiuuuuuuuuu $^{8}$

Trata-se de uma poesia advinda da observação do poeta em face do mundo que o rodeava, de sua experiência de residir em Duque de Caxias e de trabalhar, nos anos 1940, na Praia Vermelha, ocasião em que tomava os trens pelas manhãs e ao final do dia. O poema acompanha o vai e vem das estações do subúrbio carioca, parodiando o antigo poema de Manuel Bandeira, "Trem de ferro", com a construção de uma onomatopeia que imita a movimentação de cada parada e cada partida de trem. Tais movimentos, como recurso literário de expressão poética, deflagram, por sua vez, uma situação social de denúncia realizada pelo poeta: "tem gente com fome / tem gente com fome / tem gente com fome".

\section{DA AUSÊNCIA À EXISTÊNCIA}

Como anuncia o grande pensador camaronês Achille Mbembe, o pensamento europeu, dentro de sua lógica colonialista, nunca operou a identidade como forma de pertencimento mútuo, como forma de construção de um território de encontro respeitoso com a diferença. Muito pelo contrário, como orientava o aparelho colonial em funcionamento. Dentro de uma lógica euro-americana, que Mbembe caracterizou como um tipo de autoficção ou de autocontemplação do colonizador, os termos negro e raça aparecem no saber e no discurso

ao reduzir o corpo e o ser vivo a uma questão de aparência, de pele e de cor, outorgando à pele e à cor o estatuto de uma ficção de cariz biológico, os mundo 
euro-americanos em particular fizeram do negro e da raça duas versões de uma única e mesma figura: a da loucura codificada?

Do século XV ao século XIX, construiu-se um grande maquinário social, regrado pelo pensamento eurocêntrico, com o propósito de transformar em mercadoria homens e mulheres que habitavam a África. Tal experiência profundamente dilacerante a tais pessoas, que são tragadas por um sistema colonial de exploração e espoliação da própria existência, criou uma população-objeto ou uma população-mercadoria, renegando a todas essas pessoas a própria língua e a manutenção de laços sociais. Ainda assim, em que pesem todas as dificuldades inimagináveis para nós contemporâneos, tais pessoas, impedidas de realizar uma vivência digna, não deixaram, num ato de resistência, de ter o estatuto de sujeitos ativos no mundo. Mbembe demarca muito bem essa dualidade exploração/resistência:

Humilhado e profundamente desonrado, o negro é, na ordem da modernidade, o único de todos os humanos cuja carne foi transformada em coisa e o espírito em mercadoria - cripta viva do capital. Porém - e esta é sua patente dualidade -, numa reviravolta espetacular, tornou-se o símbolo de um desejo consciente de vida, força pujante, flutuante e plástica, plenamente engajada no ato de criação e até mesmo no ator de viver em vários tempos e várias histórias simultaneamente ${ }^{10}$.

É possível dizer que a poesia de Solano Trindade se liga exatamente a essa dualidade. Ele vai ao passado de humilhações, da exploração e da resistência das populações negras não para tão somente rememorar, mas como um ato de dar existência ao que estava até então ausente. O poeta sabia do espaço a preencher: na ausência, não há poder constituído. Em termos comparativos, é preciso lembrar o que Grada Kilomba, no prefácio à mais recente edição brasileira da obra Pele negra, máscaras brancas, de Frantz Fanon, relatou sobre sua experiência de estudante universitária em Lisboa, no final dos anos 1990. Num momento em que escrevia o seu trabalho de diplomação, ela percorria os muitos livros na biblioteca e ficava a se perguntar: "como é que se pode escrever sobre a negritude, num espaço onde não há um único livro escrito por autorxs negrxs?" . Sua constatação é que havia um princípio da ausência, como descreve: "Este princípio da ausência, no qual algo que existe é tornado ausente, é uma das bases fundamentais do racismo". As obras de Frantz Fanon existem, mas são ausentes, e por isso deixam de ter existência real. O existente passa a ser ausente e deixa assim de existir"12.

O princípio de existência em Solano Trindade se faz, em muitos casos, por meio de uma poesia que observa e plasma a realidade ou, no jogo com a memória do passado, reage e se conecta com as raízes da experiência histórica do escravismo colonial e suas lutas de resistência. É o caso do poema "Sou negro", dedicado a Dione Silva:

Sou Negro

meus avós foram queimados

pelo sol da África

minh'alma recebeu o batismo dos tambores

atabaques, gonguês e agogôs
9. MBEMBE, Achille. Crítica da razão negra. Tradução de Sebastião Nascimento. São Paulo: N-1 Edições, 2018, p. 13

10. Ibidem, p. 21.

11. KILOMBA, Grada. Fanon, existência, ausência. In: FANON, Frantz. Pele negra, máscaras brancas. Tradução de Sebastião Nascimento e Raquel Camargo. São Paulo: Ubu, 2020, p. 12 , grifos da autora. 12. Ibidem, p. 12, grifos da autora. 
comunicação \& educação • Ano XXVI • número 1 • jan/jun 2021

Contaram-me que meus avós

vieram de Loanda

como mercadoria de baixo preço

plantaram cana pro senhor do engenho novo

e fundaram o primeiro Maracatu.

Depois meu avô brigou como um danado

nas terras de Zumbi

Era valente como quê

$\mathrm{Na}$ capoeira ou na faca

escreveu não leu

o pau comeu

Não foi um pai João

humilde e manso.

Mesmo vovó

não foi de brincadeira

Na guerra dos Malés

ela se destacou.

$\mathrm{Na}$ minh'alma ficou

o samba

o batuque

o bamboleio

e o desejo de libertação ${ }^{13}$.

Essa conexão com o passado é uma forma de mobilização da memória em torno da experiência colonial, incidindo sobre a apropriação das imagens que representaram as lutas do passado e como tais imagens podem se ocupar e suscitar a própria luta no presente. Não se trata, por parte do poeta, de um testemunho, mas, sim, de uma evocação que leva à crítica do seu próprio tempo. Nesse sentido, a memória não recupera em si a injustiça antes cometida com tais populações - muito menos se ancora numa chave melancólica ou nostálgica -, mas restitui e coloca em circulação as contradições de uma situação colonial ainda vivida no presente. A experiência dos seus avôs, num ato autobiográfico do poeta, representa o gesto do passado, que se transforma para o poeta numa espécie de espelho e se torna o ponto de encontro de algumas imagens: a sua própria que deseja a libertação plena e a imagem que carrega e tem força didática de lembrar o passado colonial e suas fontes de crueldade.

Em "Navio negreiro", o poeta percorre de maneira crítica um dos momentos mais tristes e dolorosos de nossa história: a chegada dos navios e com eles os corpos que seriam instrumentalizados pela máquina colonial:

Lá vem o navio negreiro

Lá vem ele sobre o mar

Lá vem o navio negreiro

Vamos minha gente olhar...

Lá vem o navio negreiro

Por água brasiliana 
Lá vem o navio negreiro

Trazendo carga humana...

Lá vem o navio negreiro

Cheio de melancolia

Lá vem o navio negreiro

Cheinho de poesia...

Lá vem o navio negreiro

Com carga de resistência

Lá vem o navio negreiro

Cheinho de inteligência... ${ }^{14}$

O navio negreiro de Solano Trindade evoca os ritmos e a cadência musical de antigos cantos com um verso que demarca um tipo de repetição e de marcação: "Lá vem o navio negreiro". Tais navios - já cantado, por sinal, pelo nosso grande poeta romântico Castro Alves - representavam a própria violência da expatriação. Violência, esta, que se sustenta pelo comportamento diário do colonizador em seu trato com o colonizado; violência que se dá a qualquer forma de lembrança do passado do colonizado; violência de enorme contundência na medida em que a única expectativa futura dada ao colonizado é simplesmente aquilo que se repetirá (sem dia para acabar) como sofrimento ${ }^{15}$. O poema propõe, todavia, em meio a tudo isso, uma reversão rumo à resistência e à identificação, por conseguinte à própria existência. Chegavam da África "cheinho de poesia", "cheinho de inteligência", "com carga de resistência”.

Em outro poema, intitulado "Quem tá gemendo?”, Solano Trindade aponta as mesmas feridas abertas da escravidão:

Quem tá gemendo

Negro ou carro de boi?

Carro de boi geme quando quer

Negro não

Negro geme porque apanha

Apanha pra não gemer

Gemido de negro é cantiga

Gemido de negro é poema

Geme na minh'alma,

A alma do Congo,

Do Níger da Guiné,

De toda África enfim

A alma da América

A alma Universal

Quem tá gemendo

Negro ou carro de boi? ${ }^{16}$

O verbo gemer, amplamente utilizado no poema, cria uma espécie de oposição de sentidos. Primeiro, seu sentido aponta a própria condição de humilhação

4. TRINDADE Solano. op.

cit., 1999, p. 45 
representada pela invasão de negros e negras açoitados em nome da máquina colonial; segundo esta lógica da crueldade, "Negro geme porque apanha / Apanha pra não gemer”. Se há uma forma de submissão, é porque o regime colonial e suas formas de acumulação não permitiram outra saída; para o comando do colonizador sobre o colonizado "requer, acima de tudo, o poder de impor o silêncio do nativo" ${ }^{17}$. Em outro poema, intitulado "Canto dos Palmares", esse mesmo lugar do colonizador também está bem demarcado: "o opressor se dirige / a nossos campos, / seus soldados / cantam manchas de sangue"18. A partir da segunda estrofe de "Quem tá gemendo?", o sentido de gemer se transforma, opondo-se ao antes estabelecido. Por esse novo sentido, uma voz restitui um outro eu, uma nova existência liberta da tutela do colonizador. Seu gemido se converte em cantiga, em poema, se lança como grito de liberdade contra a anticomunidade, que é a colônia. Numa imagem de forte identificação, o poeta escreve: "geme na minh'alma”. Confluem-se as mesmas imagens análogas àquelas trazidas no fechamento do poema "Canto dos Palmares":

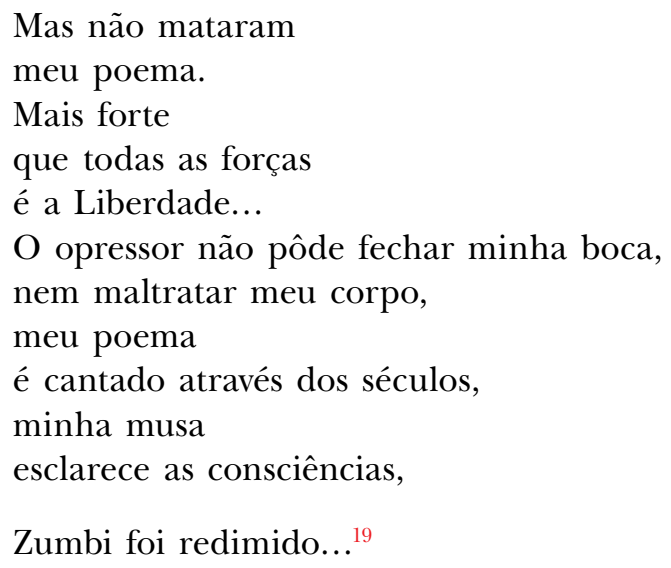

Para fechar este texto, nada parece ser mais oportuno do que o seu poema "Convocação". É preciso mais do que nunca garantir a defesa de um Estado que conviva e respeite as diferenças, um mundo em que a condição de opressão sobre populações mais pobres não prevaleça. É necessário, enfim, que a nossa poesia seja antifascista sempre, tal como a de Solano Trindade.

Contra o fascismo, Marchemos, camaradas, A liberdade nos chama, Para o dia de amanhã, Deixemos os nossos lares, Deixemos as amadas,

Partamos para a frente, Partamos, camaradas!

Contra o fascismo, Marchemos, camaradas, Soframos nesta noite Por grande amanhecer, 
É mais belo o sol, Depois das enxurradas, Partamos para a frente, Partamos, camaradas!

Contra o fascismo, Marchemos, camaradas, Vamos libertar $\mathrm{O}$ trabalhador, Das terras que ficaram Ao nazismo escravizadas, Partamos para a frente, Partamos, camaradas!

Contra o fascismo, Marchemos, camaradas, Teremos a nossa parte Na salvação do mundo, Como as das estepes, As nossas avançadas, Partamos para a frente, Partamos, camaradas! $!^{20}$

\section{REFERÊNCIAS BIBLIOGRÁFICAS}

BASTIDE, Roger. [Correspondência]. Destinatário: Solano Trindade. São Paulo, 4 out. 1946. 1 carta pessoal. In: TRINDADE, Solano. Seis tempos de poesia. São Paulo: H. Mello, 1958, p. 87.

KILOMBA, Grada. Fanon, existência, ausência. In: FANON, Frantz. Pele negra, máscaras brancas. Tradução de Sebastião Nascimento e Raquel Camargo. São Paulo: Ubu, 2020. p. 11-16.

MBEMBE, Achille. Crítica da razão negra. Tradução de Sebastião Nascimento. São Paulo: N-1, 2018.

POESIA Negra, social e mística no livro de Solano Trindade. Diário da Noite, São Paulo, 6 out. 1961.

TRINDADE, Solano. Seis tempos de poesia. São Paulo: H. Mello, 1958.

TRINDADE, Solano. Cantares ao meu povo. 2. ed. São Paulo: Brasiliense, 1981.

TRINDADE, Solano. Solano Trindade: o poeta do povo. Organização de Raquel Trindade. São Paulo: Cantos e Prantos, 1999.

TRINDADE, Solano. Poemas antológicos de Solano Trindade. Organização de Zenir Campos Reis. São Paulo: Nova Alexandria, 2011. 